\title{
Do exist gender differences in skin temperature of lower limbs following exercise test in male and female cross-country skiers?
}

\author{
M. Binek ${ }^{1} \cdot$ Z. Drzazga ${ }^{1}$ (D) T. Socha ${ }^{2} \cdot$ I. Pokora ${ }^{3}$
}

Received: 12 November 2020 / Accepted: 24 August 2021 / Published online: 18 September 2021

(c) The Author(s) 2021

\begin{abstract}
The aim of study was to assess the skin temperature changes over selected muscles zones of the lower limbs following an exercise performed at similar relative external workload in 10 male and 6 female high-trained cross-country skiers. The first stage of experiment involved preliminary exercise to determine individual oxygen uptake $\mathrm{VO}_{2 \max }$ and anaerobic threshold. The second stage experimental exercise consisted of 60 min running on treadmill with $80 \%$ of determined $\mathrm{VO}_{2 \max }$ Thermographic imaging of lower limbs was performed, before, immediately after exercise and during recovery. Physiological parameters: $\mathrm{VO}_{2}$, MET-metabolic energy equivalent, heart rate and internal temperature were assessed at rest and at the end of exercise, respectively. Infrared thermography showed that at rest the skin temperature over lower limb muscles was significantly higher in men than in women. In response to exercise an increase in skin temperature over the studied muscles was significantly higher in women than men. Since was no significant difference in skin temperature in men and women after exercise. Before the test, no physiological parameter was significantly different in women and men. Exercise test reveled significant differences between men and women in some physiological parameters such as $\mathrm{VO}_{2}$ and MET. Our study showed that there are significant differences in lower limbs skin temperature between male and female at rest but not at the end of exercise test. Women in comparison with men had a greater increase in skin temperature in response to exercise and a persistence of elevated temperature over muscles of lower limbs after exercise.
\end{abstract}

Keywords Thermal mapping · Skin temperature $\cdot$ Gender $\cdot$ Lover limbs $\cdot$ Exercise

\section{Introduction}

The local skin temperature is the result of the balance between metabolic heat production, heat dissipation to the environment and tissue temperature. This balance is mainly influenced by the internal body temperature, the ambient temperature and the complex relationship between

Z. Drzazga

zofia.k.drzazga@gmail.com

1 Department of Medical Physics, The Silesian Centre for Education and Interdisciplinary Research, A. Chełkowski Institute of Physics, University of Silesia in Katowice, Katowice, Poland

2 Department of Exercise and Sport Performance, Institute of Sport Sciences, The Jerzy Kukuczka Academy of Physical Education in Katowice, Katowice, Poland

3 Department of Physiological-Medical Sciences, Institute of Sport Sciences, The Jerzy Kukuczka Academy of Physical Education in Katowice, Katowice, Poland the dilation of blood vessels in the skin and perspiration, which facilitate heat exchange to the environment [1]. The skin plays very important role in thermoregulation. The distribution of body surface temperatures depends on microvascular function and may differ in individuals with different body mass, compositions and body surface area. It is thought that gender can be an independent modulator of skin vasomotor and sudomotor functions during heat exposure. Women differ from men in their thermal response to exogenous heat load and heat loss, as well as to endogenous heat load during exercise, as they typically have larger ratio of body surface to body mass, a higher subcutaneous adipose tissue content, a lower exercise capacity and a lower blood volume [2-4]. It was has been indicated that compared to normal weight individuals, obese people show increased heat dissipation from the limbs (especially hands) and less heat dissipation from the abdomen [5]. Chudecka et al. showed that only in the area of the chest mean skin temperature was significantly higher in women than in men, while in the other areas of 
body surface, mean skin temperature $\left(\mathrm{Tsk}_{\text {mean }}\right)$ was significantly lower in women.

Several researchers have observed gender differences in autonomously controlled heat loss pathways (skin vasomotor and sudomotor activities) during heat exposure [6-10]. Nevertheless, it has been hypothesized that when assessed during compensated exercises, which elicits the same heat loss demand in participants, gender differences in thermoeffectors can be explained by differences in body surface area to body weight ratio [10]. In the post-exercise period, cutaneous blood flow and sweating return to pre-exercise levels despite a sustained increase in internal temperature, suggesting a change in thermoregulatory control. The temperature response in each part of the body can also vary during the recovery period because the trained muscular regions involved in movement exhibit a higher metabolic activity and a faster energetic and tissue recovery facilitated by their increased blood supply.

Many articles show that IRT (Infrared Thermography) as non-invasive and easy to perform method is useful in sports medicine to evaluation of skin temperature changes during and after endurance exercise [11-17]. In professional sport, as much information about the athletes as possible is needed, and thermal imaging allows to collect them because of skin thermal response depends on body fluid homeostasis, cardiovascular fitness, muscle metabolism and athlete's health. Some papers suggest that IRT can be useful to better plan an athlete's training [11-13]. In additional IRT screening of individual muscles can be useful to find overloads and injuries [14]. Marins et al. [13] presented a strong evidence supported differences in thermal characteristics between genders, regardless of the measurement techniques IRT.

Cross-country skiing is one of the most demanding sports with an emphasis on endurance and high muscle efficiency, mainly in the legs and upper limbs, so thermal mapping appears to be useful for assessing gender differences in athlete performance and gender differences in lower limb skin temperature after an exercise test. Analyses of skin temperature changes can have diagnostic value for sports performance [15]. Thermal mapping is a very useful, inexpensive, and rapid method to evaluate the changes in skin surface temperature [16], which can be also used to evaluate physiological regulatory mechanisms associated with exercise [17].

However, according to our knowledge, there is not any paper investigated this problem in cross-country skiers. We hypothesize that there are gender differences in lower limbs temperature in response to similar exercise in trained male and female subjects. The aim of study was to assess the distribution and skin temperature changes over selected muscles zones of the lower limbs in response to an exercise performed at similar relative external workload (Power [W $\left.\mathrm{kg}^{-1}\right]$ ) in male and female high-trained cross-country skiers.

\section{Material and methods}

\section{Subjects}

Our research group consisted of 10 men $(22 \pm 3.23$ years $)$ and 6 women $(23.7 \pm 3.15$ years $)$ practicing cross-country skiing. They were healthy students of the Jerzy Kukuczka Academy of Physical Education in Katowice, and members of the Polish Cross-Country Skiing National Team. All of participants were healthy and had no cardiovascular disorders before. Participants were instructed to avoid alcohol, smoking, caffeine, large meals and cosmetics before the assessment. Volunteers were informed of the purpose, possible risks and the benefits of the study before giving their written consent to participate. The study protocol followed the ethical guidelines of the World Medical Association Declaration of Helsinki and was approved by the Ethics Committee of the Jerzy Kukuczka Academy of Physical Education in Katowice, Poland [(Approval no. U2/2016)].

A week before the start of the experiment all the volunteers participated in standard incremental exercise test to determine the individual aerobic capacity $\left(\mathrm{VO}_{2 \max }\right)$ and the individual anaerobic threshold (PPA). The $\mathrm{VO}_{2 \max }$ test consisted an running on treadmill exercise to exhausted, starting on $6 \mathrm{~km} / \mathrm{h}$ and gradient set on $0 \%$ and successively increasing the pace and gradient of treadmill every $3 \mathrm{~min}$ until volitional exhaustion each participant. All details of used preliminary testing for determining of the mention values were analogical as in our earlier paper [11].

The PPA had been used to calculate target work rates for submaximal exercise testing, which were using during experimental test. The power value reached at PPA was used to calculate the target running speeds in the submaximal exercise test that was used during the experimental study.In main stage of study the subject performed experimental exercise (EET) consisted of 60 min running on treadmill treadmill at the intensity equal to $80 \%$ of their individual lactate threshold intensity. Research was performed in the Human Performance Laboratory at the Academy of Physical Education in Katowice on treadmill $\mathrm{H} / \mathrm{P}$ (a Cosmed treadmill, Germany), at $20 \pm 1{ }^{\circ} \mathrm{C}$ ambient temperature, $56 \pm 3 \%$ relative humidity and $985 \pm 5 \mathrm{hPa}$ atmospheric pressure.

\section{Measures}

\section{Somatic and physiological characteristics}

Prior to the study, somatic parameters (body mass, and body composition), were assessed by the bioimpedance 
method (InBody, Korea), and body surface area (BSA) as well as BSA/BM were calculated. At the beginning and at the end of exercise test oxygen uptake $\left(\mathrm{VO}_{2}\right)$, minute ventilation (Ve), aural canal temperature (Tau) and heart rate (HR) were measured and metabolic energy equivalent (MET), amount of energy expended (EE) were calculated using a metabolic system (Cortex Metamax, Germany). Internal body temperature was measured from the auditory canal using an insulated, ear-molded plug and thermistor inserted into the external auditory canal (Ellab, E-valFlex model 1.38, Denmark). Heart rate (HR) was recorded telemetry at 10 -min intervals during exercise by using a sport-tester (Polar-1500PE, Finland).

\section{Thermal mapping}

Thermal images were collected before, immediately after exercise and $10 \mathrm{~min}$ after exercise. For each participant were made six photographs of legs ( 3 at front and 3 from the rear) using camera Flir Systems E60, resolution of camera 320 X 240 pixels, sensitivity $0.05 \mathrm{~K}$. Camera was calibrated by black body, the emissivity was set at the range of 0.97-0.98. Thermal images were made in accordance with the Glamorgan Protocol [18] and taking into consideration checklist directed at standardizing thermographic imaging in sports and exercise medicine Moreira et al. [16]. The results were analyzed by using a ThermaCAM TM Researcher Pro 2.8 SR-3, legs were divided into muscles zones according to model by Fernandez-Cuevas et al. [19].

\section{Statistical analysis}

Results have been presented as arithmetic means $(M)$ with standard deviations (SD). Statistical analyses were performed in Statistica 12, using Student's t test and Cochran-Cox test. To check normality (Shapiro-Wilk test) and the homogeneity of variance test (Levene's $F$ test) were performed. One-way repeated measures analysis of variance (ANOVA, sex $\times$ exercise) was used to assess sex and exercise impact on physiological parameters, and post hoc Tukey's test. Effect size from One-way ANOVA was calculated because of small numbers groups of tested subjects. Correlations between physiological parameters and the mean skin temperature changes were also examined. Statistical significant was set at $p<0.05$.

\section{Results}

1. The somatic characteristics of the studied males and females are shown in Table 1. Statistical analysis of the examined characteristics showed that both groups were significantly different in body mass (BM), body surface
Table 1 Demographic and anthropomorphic characteristics of study participants

\begin{tabular}{lrrl}
\hline Variable & \multicolumn{1}{l}{$\begin{array}{l}\mathrm{M} \pm \mathrm{SD} \\
\mathrm{Men}(n=10)\end{array}$} & $\begin{array}{l}\mathrm{M} \pm \mathrm{SD} \\
\text { Women }(n=6)\end{array}$ & \multicolumn{1}{l}{$p$} \\
\hline Age/years & $22 \pm 3.23$ & $23.7 \pm 3.15$ & 0.29 \\
Body height/cm & $180.5 \pm 3.84$ & $165.38 \pm 8.17$ & 0.00 \\
Body mass $/ \mathrm{kg}$ & $73.76 \pm 8.11$ & $63.53 \pm 4.92$ & 0.004 \\
$\mathrm{BSA} / \mathrm{m}^{2}$ & $1.92 \pm 0.12$ & $1.70 \pm 0.10$ & 0.001 \\
$\mathrm{BMI} / \mathrm{kg} \mathrm{m}{ }^{2}$ & $22.6 \pm 1.86$ & $22.78 \pm 1.44$ & 0.84 \\
$\mathrm{FM} / \mathrm{kg}$ & $6.32 \pm 2.76$ & $11.32 \pm 1.62$ & 0.00 \\
$\mathrm{FFM} / \mathrm{kg}$ & $67.44 \pm 6.81$ & $52.31 \pm 7.28$ & 0.00 \\
\hline
\end{tabular}

$B S A$ body surface area, $B M I$ body mass index, $F M$ fat mass, $F F M$ fat free body mass

Table 2 Physiological characteristics of participants at preliminary testing

\begin{tabular}{|c|c|c|c|}
\hline Variable & $\begin{array}{l}\bar{M} \pm S D \\
\text { Men }(10)\end{array}$ & $\begin{array}{l}\bar{M}_{ \pm S D} \\
\text { Women (6) }\end{array}$ & $p$ \\
\hline $\mathrm{VO}_{2 \max } / \mathrm{mL} \mathrm{kg}^{-1} \min ^{-1}$ & $65.67 \pm 7.30$ & $53.83 \pm 4.96$ & 0.00 \\
\hline $\mathrm{HR}_{\max } / \mathrm{bs} \min ^{-1}$ & $191.44 \pm 8.44$ & $188.33 \pm 11.52$ & 0.55 \\
\hline Power $_{\text {max }} / \mathrm{W}$ & $398.78 \pm 53.34$ & $302.33 \pm 35.96$ & 0.00 \\
\hline Power $_{\max } / \mathrm{W} \mathrm{kg}^{-1}$ & $5.53 \pm 0.57$ & $4.84 \pm 0.26$ & 0.02 \\
\hline $\mathrm{Ve}_{\max } / \mathrm{L} \min ^{-1}$ & $13.99 \pm 0.03$ & $12.00 \pm 0.00$ & 0.00 \\
\hline $\mathrm{HR}_{\mathrm{AT}} / \mathrm{bs} \min ^{-1}$ & $174.89 \pm 7.75$ & $178.00 \pm 2.19$ & 0.36 \\
\hline $\mathrm{V}_{\mathrm{AT}} / \mathrm{km} \mathrm{h}^{-1}$ & $13.33 \pm 1.00$ & $12.00 \pm 0.00$ & 0.01 \\
\hline $\mathrm{G} \%_{\mathrm{AT}} 1 \%$ & $9.44 \pm 3.00$ & $9.17 \pm 1.29$ & 0.84 \\
\hline
\end{tabular}

$V O_{2 \max }$ maximal oxygen uptake, $H R_{\max }$ maximal heart rate, $H R_{\text {AT }}$ heart rate at an anaerobic threshold, $V \mathrm{e}_{\max }$ maximal pulmonary ventilation $\left[1 \mathrm{~min}^{-1}\right], G \%_{\mathrm{AT}}$ the treadmill inclination at an anaerobic threshold, $V_{\mathrm{AT}}$ run speed at an anaerobic threshold, $A T$ an anaerobic threshold, Power $_{\max }$ maximal power

area (BSA), fat mass (FM) and fat free mass (FFM) according to expectations.

2. The physiological parameters obtained in preliminary study were listed in Table 2 . They indicated the substantial gender differences in physiological parameters such as $\mathrm{VO}_{2 \max }$, Power ${ }_{\max }, \mathrm{V}_{\mathrm{e} \text { max }}$, (maximal pulmonary ventilation $\left[\mathrm{L} \mathrm{min}^{-1}\right]$ ) and $\mathrm{V}_{\mathrm{at}}$ (run speed at an anaerobic threshold) during preliminary test.

Response of body skin temperature to experimental exercise was demonstrated in thermal mapping (Fig. 1) and obtained temperatures over specified muscle zones were listed in Table 3. Figure 1 presents examples of the obtained thermographic images of front and rear of lower limbs for man and woman, respectively. Before exercise test registered temperatures were higher in man comparing to woman for all considered muscle zones. Directly after exercise an 


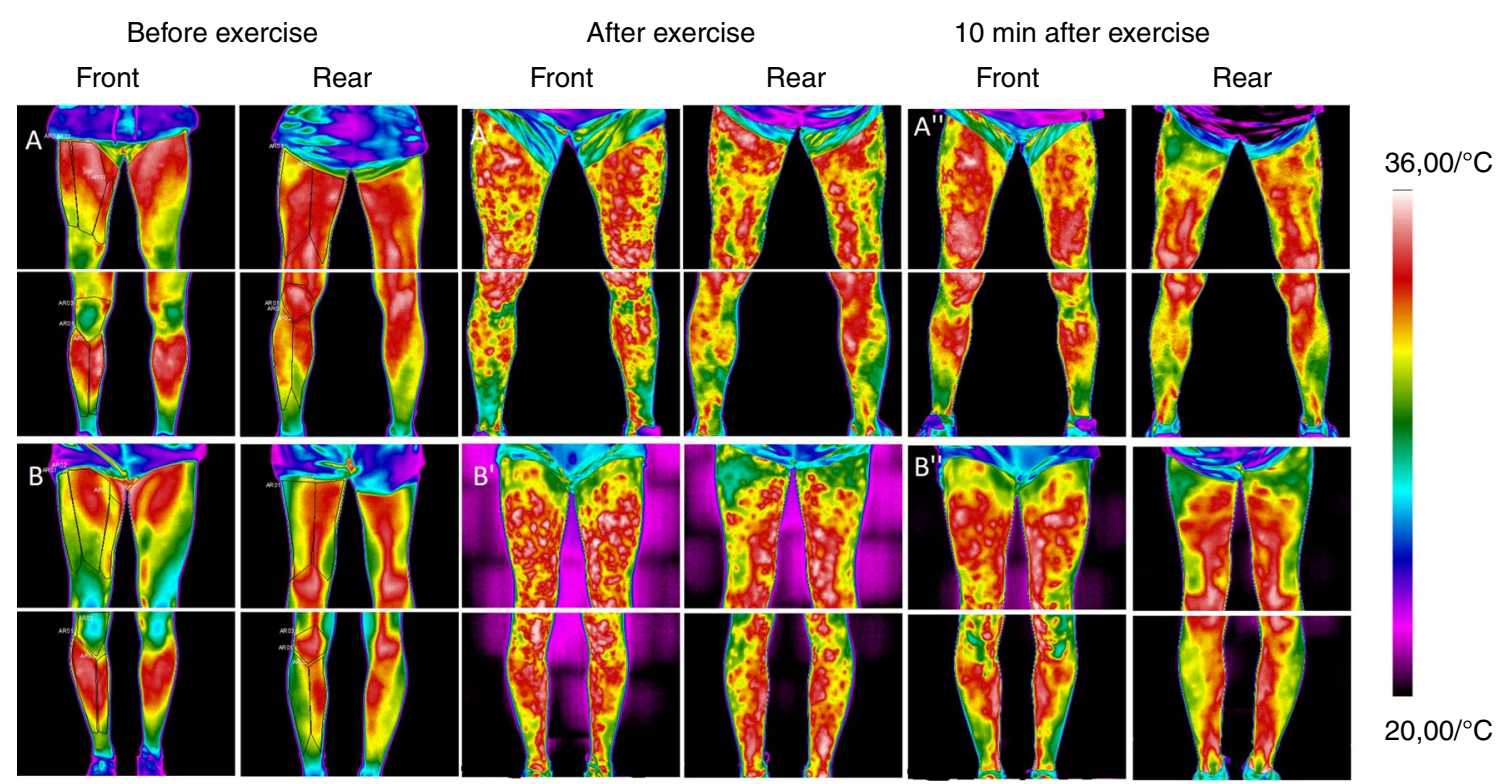

Fig. 1 Typical thermal images of front and rear lower limbs in each part of exercise. Part A-man before exercise; Part A'-man immediately after exercise; Part A"'-man 10 min after exercise; part B-

increase of temperature was observed in both groups of considered participants (A' and B' parts) However, 10 min after exercise skin temperature returned to initial level but faster in men than in women (A', vs. B").

Mean temperature values over muscle zones and over entire leg obtained before exercise $(T 1)$, immediately after exercise (T2) and after $10 \mathrm{~min}$ restitution (T3) as well as calculated changes of temperatures in response to exercise $\left(\Delta T_{2-1}=T 2-T 1\right)$, after $10 \mathrm{~min}$ restitution $\left(\Delta T_{3}-{ }_{2}=T 3-T 2\right)$ and at the end of experiment procedure $\left(\Delta T_{3}-{ }_{1}=T 3-T 1\right)$, were listed in Table 3 for male and female groups of crosscountry skiers, respectively. It should be noted that skin temperature distribution in woman and man was different, especially before EET. The obtained temperatures for men were higher than for women, Table 3.

In response to exercise an increase of skin temperature $(\Delta T 2-T 1)$ was observed in both groups, but higher rise in women than in men. Next, skin temperature dropped quicker in men than in women, caused nearly equalization of skin temperature values in both group after $10 \mathrm{~min}$ of recovery. Statistical analysis confirmed that skin temperatures of nearly all considered muscle zones (except tibialis anterior) in men differed statistically in comparison to women $p<0.05$ before EET but these temperature differences between woman and men disappeared after exercises.

There was no significant gender difference in the internal body temperature (Tau) either at rest or at the end of exercise test (Fig. 2). However exercise test induced the marked increase of the internal body temperature in men as well as women. woman before exercise; Part B'-woman after exercise; Part B', woman $10 \mathrm{~min}$ after exercise

Visualization of changes of temperature in response to exercise test and to complete experimental procedure for selected muscle zones of men and women was presented in Fig. 3.

It follows from Table 3 and Fig. $3 \mathrm{~A}$ and $\mathrm{B}$ that temperature differences after exercise and before $\left(T_{2}-T_{1}\right)$ as well as temperature changes obtained after $10 \mathrm{~min}$ recovery $\left(T_{3}-T_{1}\right)$ were markedly higher for women than for men. In addition, it should be noted that the values of temperature changes $\Delta T_{3-1}$ became negative for most of muscles zones of men legs, unlike women (except GCM), Fig. 3b.

Statistical analysis showed that nearly all calculated $\Delta T_{2-1}$ values (except muscles of rear thigh) and $\Delta T_{3}-{ }_{1}$ values (except muscles of rear calf) were statistically significant different between gender groups, $p<0.05$.

The physiological parameters of participants at the beginning and in response to the EET exercise test have been listed in Table 4. It was noticed that at the beginning of EET test, none of the examined indicators (i.e., $\mathrm{VO}_{2}, \mathrm{HR}$, Power, Power $\mathrm{BM}^{-1}$, MET, EE) differed statistically significantly between men and women. In contrast, exercise performance had an effect on the values of all assessed indices, wherein a stronger effect occurs in men than in women. One-way ANOVA test showed that statistical significant differences between men and women were obtained for: oxygen uptake $\left(\mathrm{VO}_{2}\right)$, mean power [W], metabolic energy equivalent (MET) and energy expenditure (EE), unlike hearth rate (HR), Power $\left[\mathrm{W} \mathrm{BSA}^{-1}\right.$ ] and Power [W BM ${ }^{-1}$ ].

What is more, gender statistical significant differences due to experimental exercise were also obtained 
Table 3 Temperatures of individual leg muscles zones and their mean as well as temperature changes in response to exercise $\left(\Delta T_{21}\right), 10$ min restitution $\left(\Delta T_{32}\right)$, and total experimental procedure $\left(\Delta T_{31}\right)$ for males and females

\begin{tabular}{|c|c|c|c|c|c|c|}
\hline Muscle zones & Variable & Men $(n=10) \mathrm{M} \pm \mathrm{SD}$ & Women $(n=6) \mathrm{M} \pm \mathrm{SD}$ & $p$ & $F$ & $\overline{\eta^{2} p}$ \\
\hline \multicolumn{7}{|l|}{ Front side of legs } \\
\hline \multirow[t]{6}{*}{ Vastus lateralis } & $T_{1} /{ }^{\circ} \mathrm{C}$ & $31.62 \pm 0.70$ & $29.68 \pm 0.43$ & 0.00 & - & - \\
\hline & $T_{2} /{ }^{\circ} \mathrm{C}$ & $32.36 \pm 0.74$ & $31.67 \pm 0.40$ & 0.05 & - & - \\
\hline & $T_{3} /{ }^{\circ} \mathrm{C}$ & $31.60 \pm 0.88$ & $31.41 \pm 0.91$ & 0.68 & - & - \\
\hline & $\Delta T_{21}=T_{2}-T_{1} /{ }^{\circ} \mathrm{C}$ & $0.74 \pm 0.525$ & $1.98 \pm 0.52$ & 0.00 & 94.61 & 0.87 \\
\hline & $\Delta T_{31}=T_{3}-T_{1} /{ }^{\circ} \mathrm{C}$ & $-0.02 \pm 1.10$ & $1.73 \pm 1.06$ & 0.01 & 9.21 & 0.39 \\
\hline & $\Delta T_{32}=T_{3}-T_{2} /{ }^{\circ} \mathrm{C}$ & $-0.76 \pm 0.35$ & $-0.26 \pm 0.45$ & 0.39 & 0.78 & 0.05 \\
\hline \multirow[t]{6}{*}{ Rectus femoris } & $T_{1} /{ }^{\circ} \mathrm{C}$ & $32.16 \pm 0.60$ & $30.38 \pm 0.33$ & 0.00 & - & - \\
\hline & $T_{2} /{ }^{\circ} \mathrm{C}$ & $32.44 \pm 0.63$ & $31.77 \pm 0.91$ & 0.09 & - & - \\
\hline & $T_{3} /{ }^{\circ} \mathrm{C}$ & $31.97 \pm 0.70$ & $31.66 \pm 0.90$ & 0.45 & - & - \\
\hline & $\Delta T_{21}=T_{2}-T_{1} /{ }^{\circ} \mathrm{C}$ & $0.28 \pm 0.53$ & $1.39 \pm 0.73$ & 0.00 & 28.31 & 0.66 \\
\hline & $\Delta T_{31}=T_{3}-T_{1} /{ }^{\circ} \mathrm{C}$ & $-0.19 \pm 0.75$ & $1.28 \pm 0.95$ & 0.00 & 6.45 & 0.31 \\
\hline & $\Delta T_{32}=T_{3}-T_{2} /{ }^{\circ} \mathrm{C}$ & $-0.47 \pm 0.23$ & $-0.11 \pm 0.30$ & 0.35 & 0.93 & 0.06 \\
\hline \multirow[t]{6}{*}{ Vastus medialis } & $T_{1} /{ }^{\circ} \mathrm{C}$ & $32.32 \pm 0.73$ & $30.32 \pm 0.71$ & 0.00 & - & - \\
\hline & $T_{2} /{ }^{\circ} \mathrm{C}$ & $32.78 \pm 0.68$ & $32.04 \pm 0.82$ & 0.07 & - & - \\
\hline & $T_{3} /{ }^{\circ} \mathrm{C}$ & $32.51 \pm 0.58$ & $31.87 \pm 0.85$ & 0.09 & - & - \\
\hline & $\Delta T_{21}=T_{2}-T_{1} /{ }^{\circ} \mathrm{C}$ & $0.45 \pm 0.67$ & $1.73 \pm 0.95$ & 0.01 & 29.29 & 0.68 \\
\hline & $\Delta T_{31}=T_{3}-T_{1} /{ }^{\circ} \mathrm{C}$ & $0.19 \pm 0.66$ & $1.55 \pm 1.29$ & 0.01 & 12.96 & 0.48 \\
\hline & $\Delta T_{32}=T_{3}-T_{2} /{ }^{\circ} \mathrm{C}$ & $-0.27 \pm 0.25$ & $-0.18 \pm 0.32$ & 0.82 & 0.05 & 0.00 \\
\hline \multirow[t]{6}{*}{ Knee (front) } & $T_{1} /{ }^{\circ} \mathrm{C}$ & $29.77 \pm 0.81$ & $28.79 \pm 0.73$ & 0.03 & - & - \\
\hline & $T_{2} /{ }^{\circ} \mathrm{C}$ & $31.68 \pm 1.73$ & $32.22 \pm 0.62$ & 0.47 & - & - \\
\hline & $T_{3} /{ }^{\circ} \mathrm{C}$ & $30.78 \pm 1.43$ & $31.58 \pm 1.05$ & 0.25 & - & - \\
\hline & $\Delta T_{21}=T_{2}-T_{1} /{ }^{\circ} \mathrm{C}$ & $1.91 \pm 1.66$ & $3.43 \pm 0.57$ & 0.05 & 56.94 & 0.80 \\
\hline & $\Delta T_{31}=T_{3}-T_{1} /{ }^{\circ} \mathrm{C}$ & $1.01 \pm 1.57$ & $2.79 \pm 1.07$ & 0.03 & 27.03 & 0.66 \\
\hline & $\Delta T_{32}=T_{3}-T_{2} /{ }^{\circ} \mathrm{C}$ & $-0.90 \pm 0.43$ & $-0.64 \pm 0.56$ & 0.72 & 0.13 & 0.01 \\
\hline \multirow[t]{6}{*}{ Tibialis anterior } & $T_{1} /{ }^{\circ} \mathrm{C}$ & $31.60 \pm 0.75$ & $31.18 \pm 0.59$ & 0.27 & - & - \\
\hline & $T_{2} /{ }^{\circ} \mathrm{C}$ & $31.67 \pm 0.58$ & $32.28 \pm 0.69$ & 0.08 & - & - \\
\hline & $T_{3} /{ }^{\circ} \mathrm{C}$ & $30.72 \pm 0.77$ & $31.41 \pm 1.00$ & 0.14 & - & - \\
\hline & $\Delta T_{21}=T_{2}-T_{1} /{ }^{\circ} \mathrm{C}$ & $0.08 \pm 1.02$ & $1.10 \pm 0.55$ & 0.04 & 6.69 & 0.32 \\
\hline & $\Delta T_{31}=T_{3}-T_{1} /{ }^{\circ} \mathrm{C}$ & $-0.89 \pm 1.04$ & $0.23 \pm 1.01$ & 0.05 & 1.53 & 0.10 \\
\hline & $\Delta T_{32}=T_{3}-T_{2} /{ }^{\circ} \mathrm{C}$ & $-0.96 \pm 0.34$ & $-0.87 \pm 0.44$ & 0.88 & 0.02 & 0.00 \\
\hline \multirow[t]{6}{*}{ Soleus } & $T_{1} /{ }^{\circ} \mathrm{C}$ & $31.60 \pm 0.69$ & $30.64 \pm 0.43$ & 0.01 & - & - \\
\hline & $T_{2} /{ }^{\circ} \mathrm{C}$ & $32.08 \pm 0.85$ & $32.58 \pm 0.33$ & 0.20 & - & - \\
\hline & $T_{3} /{ }^{\circ} \mathrm{C}$ & $31.37 \pm 0.83$ & $31.71 \pm 1.42$ & 0.55 & - & - \\
\hline & $\Delta T_{21}=T_{2}-T_{1} /{ }^{\circ} \mathrm{C}$ & $0.48 \pm 1.10$ & $1.93 \pm 0.43$ & 0.01 & 25.77 & 0.65 \\
\hline & $\Delta T_{31}=T_{3}-T_{1} /{ }^{\circ} \mathrm{C}$ & $-0.23 \pm 1.04$ & $1.07 \pm 1.26$ & 0.04 & 2.07 & 0.12 \\
\hline & $\Delta T_{32}=T_{3}-T_{2} /{ }^{\circ} \mathrm{C}$ & $-0.71 \pm 0.37$ & $-0.87 \pm 0.47$ & 0.80 & 0.07 & 0.00 \\
\hline \multicolumn{7}{|l|}{ Rear side of legs } \\
\hline \multirow[t]{6}{*}{ Biceps femoris } & $T_{1} /{ }^{\circ} \mathrm{C}$ & $32.03 \pm 0.75$ & $29.93 \pm 0.32$ & 0.00 & - & - \\
\hline & $T_{2} /{ }^{\circ} \mathrm{C}$ & $32.13 \pm 0.80$ & $30.73 \pm 1.32$ & 0.02 & - & - \\
\hline & $T_{3} /{ }^{\circ} \mathrm{C}$ & $31.57 \pm 0.69$ & $30.83 \pm 0.86$ & 0.08 & - & - \\
\hline & $\Delta T_{21}=T_{2}-T_{1} /{ }^{\circ} \mathrm{C}$ & $0.11 \pm 0.79$ & $0.80 \pm 1.09$ & 0.16 & 2.69 & 0.21 \\
\hline & $\Delta T_{31}=T_{3}-T_{1} /{ }^{\circ} \mathrm{C}$ & $-0.46 \pm 0.68$ & $0.89 \pm 0.76$ & 0.00 & 1.38 & 0.09 \\
\hline & $\Delta T_{32}=T_{3}-T_{2} /{ }^{\circ} \mathrm{C}$ & $-0.57 \pm 0.31$ & $0.09 \pm 0.40$ & 0.21 & 1.71 & 0.11 \\
\hline
\end{tabular}


Table 3 (continued)

\begin{tabular}{|c|c|c|c|c|c|c|}
\hline Muscle zones & Variable & $\operatorname{Men}(n=10) \mathrm{M} \pm \mathrm{SD}$ & Women $(n=6) \mathrm{M} \pm \mathrm{SD}$ & $p$ & $F$ & $\eta^{2} p$ \\
\hline \multirow[t]{6}{*}{ Remaining thighs muscle } & $T_{1} /{ }^{\circ} \mathrm{C}$ & $30.37 \pm 0.67$ & $30.64 \pm 0.32$ & 0.00 & - & - \\
\hline & $T_{2} /{ }^{\circ} \mathrm{C}$ & $32.48 \pm 0.82$ & $31.62 \pm 1.18$ & 0.11 & - & - \\
\hline & $T_{3} /{ }^{\circ} \mathrm{C}$ & $32.10 \pm 0.59$ & $31.66 \pm 0.87$ & 0.25 & - & - \\
\hline & $\Delta T_{21}=T_{2}-T_{1} /{ }^{\circ} \mathrm{C}$ & $0.11 \pm 1.02$ & $0.97 \pm 1.06$ & 0.13 & 4.13 & 0.22 \\
\hline & $\Delta T_{31}=T_{3}-T_{1} /{ }^{\circ} \mathrm{C}$ & $-0.27 \pm 0.67$ & $1.03 \pm 0.73$ & 0.00 & 4.43 & 0.24 \\
\hline & $\Delta T_{32}=T_{3}-T_{2} /{ }^{\circ} \mathrm{C}$ & $-0.38 \pm 0.25$ & $0.05 \pm 0.33$ & 0.31 & 1.09 & 0.07 \\
\hline \multirow[t]{6}{*}{ Knee (rear) } & $T_{1} /{ }^{\circ} \mathrm{C}$ & $32.95 \pm 0.49$ & $31.51 \pm 0.42$ & 0.00 & - & - \\
\hline & $\mathrm{T}_{2} /{ }^{\circ} \mathrm{C}$ & $32.55 \pm 0.86$ & $32.23 \pm 0.57$ & 0.44 & - & - \\
\hline & $T_{3} /{ }^{\circ} \mathrm{C}$ & $32.14 \pm 0.61$ & $31.74 \pm 0.81$ & 0.29 & - & - \\
\hline & $\Delta T_{21}=T_{2}-T_{1} /{ }^{\circ} \mathrm{C}$ & $-0.40 \pm 0.77$ & $0.73 \pm 0.28$ & 0.00 & 0.95 & 0.06 \\
\hline & $\Delta \mathrm{T}_{31}=\mathrm{T}_{3}-\mathrm{T}_{1} /{ }^{\circ} \mathrm{C}$ & $-0.81 \pm 0.63$ & $0.23 \pm 0.98$ & 0.02 & 2.11 & 0.13 \\
\hline & $\Delta T_{32}=T_{3}-T_{2} /{ }^{\circ} \mathrm{C}$ & $-0.42 \pm 0.27$ & $-0.49 \pm 0.34$ & 0.86 & 0.03 & 0.00 \\
\hline \multirow[t]{6}{*}{ Gastrocnemius caput mediale (GCM) } & $T_{1} /{ }^{\circ} \mathrm{C}$ & $32.10 \pm 0.51$ & $30.85 \pm 0.75$ & 0.00 & - & - \\
\hline & $T_{2} /{ }^{\circ} \mathrm{C}$ & $32.06 \pm 0.65$ & $31.63 \pm 0.41$ & 0.16 & - & - \\
\hline & $T_{3} /{ }^{\circ} \mathrm{C}$ & $31.62 \pm 0.67$ & $31.22 \pm 0.89$ & 0.33 & - & - \\
\hline & $\Delta T_{21}=T_{2}-T_{1} /{ }^{\circ} \mathrm{C}$ & $-0.04 \pm 0.56$ & $0.77 \pm 0.91$ & 0.04 & 4.07 & 0.22 \\
\hline & $\Delta T_{31}=T_{3}-T_{1} /{ }^{\circ} \mathrm{C}$ & $-0.48 \pm 0.76$ & $0.38 \pm 1.05$ & 0.07 & 0.06 & 0.00 \\
\hline & $\Delta T_{32}=T_{3}-T_{2} /{ }^{\circ} \mathrm{C}$ & $-0.44 \pm 0.31$ & $-0.44 \pm 0.39$ & 0.99 & 0.00 & 0.00 \\
\hline \multirow[t]{6}{*}{ Gastrocnemius caput laterale (GCL) } & $T_{1} /{ }^{\circ} \mathrm{C}$ & $32.03 \pm 0.70$ & $30.57 \pm 0.17$ & 0.00 & - & - \\
\hline & $T_{2} /{ }^{\circ} \mathrm{C}$ & $32.02 \pm 0.85$ & $31.54 \pm 0.76$ & 0.28 & - & - \\
\hline & $T_{3} /{ }^{\circ} \mathrm{C}$ & $31.42 \pm 0.46$ & $31.10 \pm 1.13$ & 0.44 & - & - \\
\hline & $\Delta T_{21}=T_{2}-T_{1} /{ }^{\circ} \mathrm{C}$ & $-0.01 \pm 0.62$ & $0.98 \pm 0.92$ & 0.02 & 6.36 & 0.31 \\
\hline & $\Delta T_{31}=T_{3}-T_{1} /{ }^{\circ} \mathrm{C}$ & $-0.61 \pm 0.62$ & $-0.44 \pm 1.08$ & 0.69 & 6.25 & 0.31 \\
\hline & $\Delta T_{32}=T_{3}-T_{2} /{ }^{\circ} \mathrm{C}$ & $-0.60 \pm 0.26$ & $-0.40 \pm 0.34$ & 0.65 & 0.21 & 0.01 \\
\hline \multirow[t]{6}{*}{ Leg (mean) } & $T_{1} /{ }^{\circ} \mathrm{C}$ & $31.87 \pm 0.52$ & $30.41 \pm 0.36$ & 0.00 & - & - \\
\hline & $\mathrm{T}_{2} /{ }^{\circ} \mathrm{C}$ & $32.21 \pm 0.59$ & $31.84 \pm 0.60$ & 0.26 & - & - \\
\hline & $T_{3} /{ }^{\circ} \mathrm{C}$ & $31.62 \pm 0.48$ & $31.47 \pm 0.87$ & 0.67 & - & - \\
\hline & $\Delta T_{21}=T_{2}-T_{1} /{ }^{\circ} \mathrm{C}$ & $0.34 \pm 0.63$ & $1.44 \pm 0.52$ & 0.00 & 33.94 & 0.71 \\
\hline & $\Delta T_{31}=T_{3}-T_{1} /{ }^{\circ} \mathrm{C}$ & $-0.25 \pm 0.62$ & $0.98 \pm 0.89$ & 0.01 & 3.69 & 0.21 \\
\hline & $\Delta T_{32}=T_{3}-T_{2} /{ }^{\circ} \mathrm{C}$ & $-0.59 \pm 0.22$ & $-0.37 \pm 0.29$ & 0.56 & 0.35 & 0.02 \\
\hline
\end{tabular}

$T_{1}$-temperature obtained before exercise; $T_{2}$-temperature obtained immediately after exercise; $T_{3}$-temperature obtained 10 min after exercise; $\Delta T_{21}=T_{2}-T_{1}$-calculated temperature changes between end of exercise and start of exercise; $\Delta T_{31}=T_{3}-T_{1}$-calculated temperature changes between end of restitution time and start of exercise; $\Delta T_{32}=T_{3}-T_{2}$-calculated temperature changes between end of end of restitution time and end of exercise

for $\Delta \mathrm{VO}_{2}, \Delta$ Power $[\mathrm{W}]$ and $\Delta \mathrm{MET}$ but no for $\Delta$ Power $\left[\mathrm{W} \cdot \mathrm{BM}^{-1}\right], \Delta$ Power $\left[\mathrm{W} \cdot \mathrm{BSA}^{-1}\right]$ and $\Delta \mathrm{HR}$.

In addition, the use of ANOVA systems with repeated measures made it possible to find interactions between gender and exercise performance, additionally (Table 4). There was a significant interaction between gender and effort on the $\mathrm{VO}_{2}$, MET and EE values achieved in the research, according to expectations. However, no significant correlations were obtained between physiological parameters and the mean skin temperature changes.

\section{Discussion}

Metabolic energy expenditure is proportional to body mass during exercise such as treadmill walking [20]. The research assumed that all participants in this experiment would exercise with the same relative to BM, external workload. This work intensity should not result in differences in the metabolic heat production during exercise and thus in the total heat loss requirements. Hence, this 


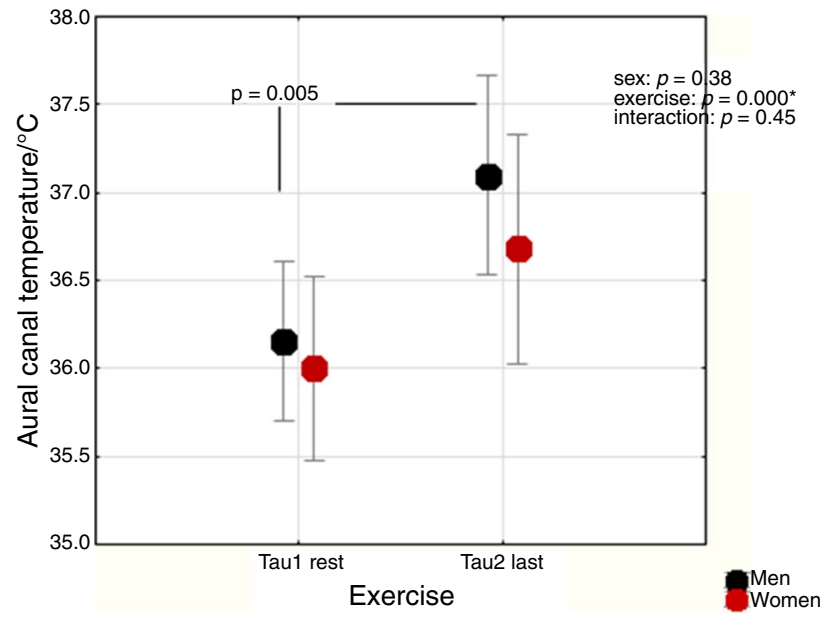

Fig. 2 Internal (aural canal) temperature $/{ }^{\circ} \mathrm{C}$ at rest and at the end of exercise test (last) in male and female subjects

exercise test should not result inconsistent changes in body temperature in individuals of different body size and aerobic capacity [21-24]. In this research approach, it was planned to have greater certainty that sex differences in thermo-effector (skin) function would be due to changes and differences in participants' thermal and hemodynamic responses, and to a lesser extent by morphological differences. In addition, in this study work intensity was related to each participant's body surface area (area-specific work rate), as this approach was found to be most effective for obtaining equivalent changes in mean body temperature across morphologically diverse individuals [10].

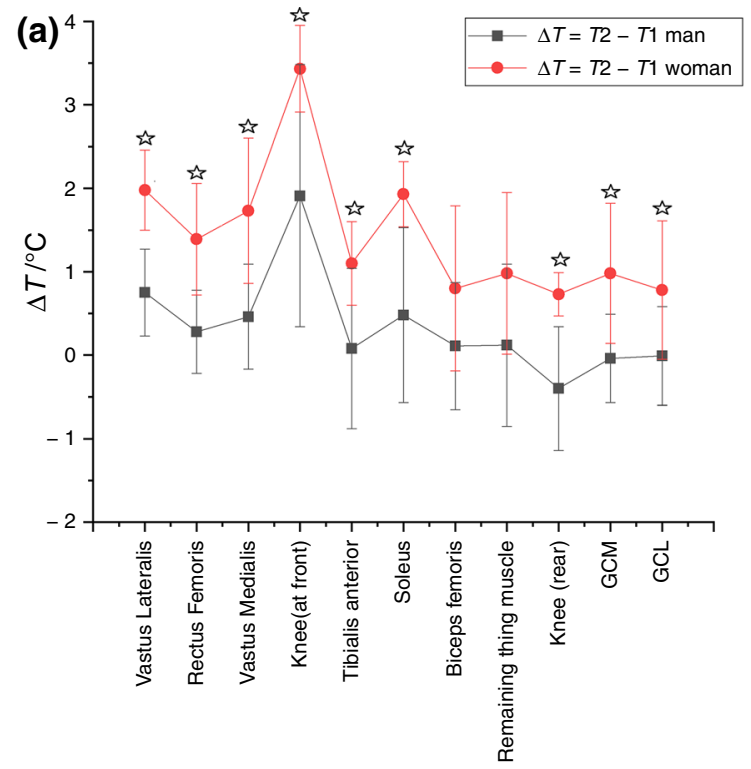

Taking into account physiological characteristics of studied participants it is worth to noted that significant differences occurred in $\mathrm{VO}_{2}$, MET and EE between male and female in response to exercise test performed at the similar external workload $\left[\mathrm{W} \mathrm{kg}^{-1}\right.$ and $\left.\mathrm{W} \mathrm{m}^{-2}\right]$. The higher oxygen uptake, MET and EE at the end of exercise test indicate, the intensity of metabolic processes and energy expenditure, including metabolic heat production were greater in men than in women. Gagnon and Kenny [9] elicited the same requirement for heat loss in males and females. The authors observed that whole-body sudomotor activity did not differ significantly between males and females during the two exercise periods $\left(200,250 \mathrm{~W} \mathrm{~m}^{-2}\right)$, becoming greater in males during the last exercise period equal to $300 \mathrm{~W} \mathrm{~m}^{-2}$ ). Apart from, sex differences in local sudomotor activity were only evidenced at the highest requirement for heat loss employed. On the other hand, when both sexes exercised at the same percentage of $\mathrm{VO}_{2 \max }$, it was generally found that females had lower end-exercise core temperature despite having lower sweat rates. However, both exercise protocols contained inherent methodological issues due to the fact that males and females were not matched for body mass. Analysis of the characteristics of our studied group revealed differences in body height, body weight, body surface area, BMI ratio, and the percentage and mass body composition between women and men. Notley et al. [10] indicated that individuals differing in body size, shape and composition appear to respond quantitatively differently to variations in both ambient and core temperatures, but the interrelations between morphological components and temperature regulation are complex.

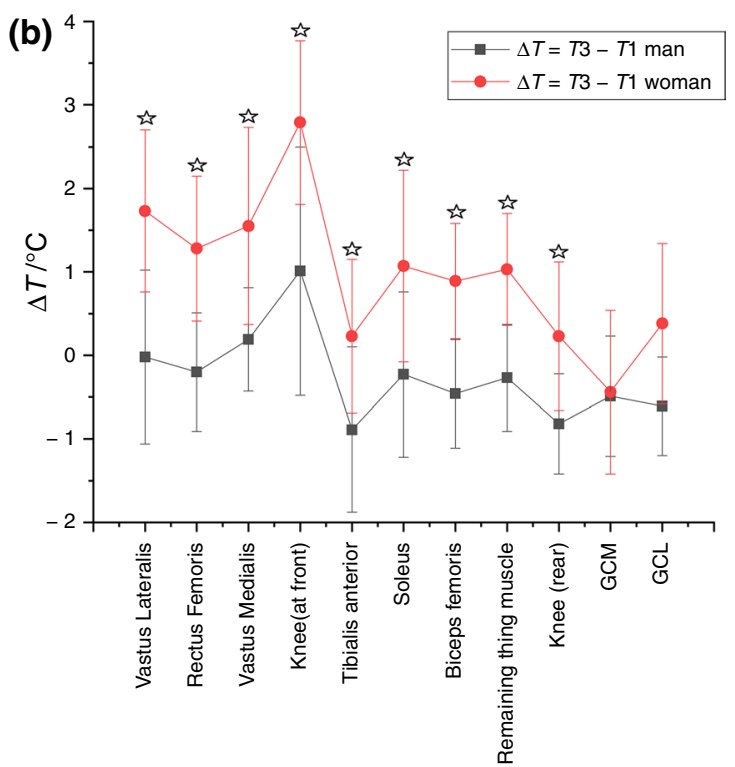

Fig. 3 Differences of temperature $/{ }^{\circ} \mathrm{C}$ for each muscle zones: a $\Delta T_{2-1}$-in response to exercise, $\mathbf{b} \Delta T_{3-1}$-in response to complete experimental procedure, respectively 
Table 4 Physiological characteristics of study participants at the beginning and at the end of exercise test for men and women respectively

\begin{tabular}{|c|c|c|c|c|c|c|c|c|}
\hline \multirow[t]{2}{*}{ Variable } & \multirow[t]{2}{*}{ Men $(n=10) \mathrm{M} \pm \mathrm{SD}$} & \multirow[t]{2}{*}{ Women $(n=6) \mathrm{M} \pm \mathrm{SD}$} & \multicolumn{3}{|c|}{ One-way ANOVA } & \multicolumn{3}{|c|}{$\begin{array}{l}\text { ANOVA—systems with repeated } \\
\text { measures }\end{array}$} \\
\hline & & & $p$ & $F$ & $\eta^{2} p$ & $\begin{array}{l}\text { Sex: } \\
F(\mathrm{~s}) \\
P \\
\eta^{2} p\end{array}$ & $\begin{array}{l}\text { Exercise: } \\
F(\mathrm{~s}) \\
P \\
\eta^{2} p\end{array}$ & $\begin{array}{l}\text { Exercise*sex } \\
F(\mathrm{~s}) \\
P \\
\eta^{2} p\end{array}$ \\
\hline $\mathrm{VO}_{2 \text { start }} / \mathrm{mL} \cdot \mathrm{kg}^{-1} \cdot \mathrm{min}^{-1}$ & $10.93 \pm 0.68$ & $10.23 \pm 0.83$ & 0.53 & 0.4225 & 0.03 & 6.33 & 337.56 & 5.35 \\
\hline $\mathrm{VO}_{2 \mathrm{l} \mathrm{end}} / \mathrm{mL} \mathrm{kg}^{-1} \mathrm{~min}^{-1}$ & $52.07 \pm 5.47$ & $41.00 \pm 10.62$ & 0.02 & 6.2726 & 0.33 & 0.022 & 0.00 & 0.037 \\
\hline$\Delta \mathrm{VO} 2 / \mathrm{mL} \mathrm{kg}^{-1} \mathrm{~min}^{-1}$ & $40.78 \pm 2.47$ & $31.00 \pm 3.02$ & 0.03 & 6.2881 & 0.33 & 0.33 & 0.96 & 0.29 \\
\hline $\mathrm{HR}_{\mathrm{start}} / \mathrm{bs} \min ^{-1}$ & $84.44 \pm 4.90$ & $85.83 \pm 6.00$ & 0.86 & 0.0321 & 0.00 & 0.037 & 762.17 & 0.46 \\
\hline $\mathrm{HR}_{\text {end }} / \mathrm{bs} \min ^{-1}$ & $184.22 \pm 2.79$ & $180.83 \pm 3.41$ & 0.46 & 0.592 & 0.04 & 0.851 & 0.00 & 0.51 \\
\hline$\Delta \mathrm{HR} / \mathrm{bs} \cdot \min ^{-1}$ & $99.78 \pm 4.36$ & $96.00 \pm 5.34$ & 0.74 & 0.2998 & 0.02 & 0.00 & 0.98 & 0.03 \\
\hline Power $_{\text {start }} / \mathrm{W}$ & $80.33 \pm 3.54$ & $69.17 \pm .33$ & 0.06 & 3.9839 & 0.23 & 6.09 & 466.98 & 6.19 \\
\hline Power $_{\text {end }} / \mathrm{W}$ & $283.67 \pm 13.43$ & $230.50 \pm 16.44$ & 0.03 & 6.2704 & 0.33 & 0.03 & 0.00 & 0.03 \\
\hline$\Delta$ Power/W & $203.33 \pm 10.67$ & $161.33 \pm 13.07$ & 0.03 & 6.1944 & 0.32 & 0.32 & 0.97 & 0.32 \\
\hline Power mass ${ }^{-1}$ start $/ \mathrm{W} \mathrm{kg}^{1}$ & $1.09 \pm 0.01$ & $1.07 \pm 0.02$ & 0.33 & 1.00 & 0.07 & 0.68 & 683.35 & 0.44 \\
\hline Power mass ${ }^{-1}$ end $/ \mathrm{W} \mathrm{kg}^{1}$ & $3.86 \pm 0.13$ & $3.71 \pm 0.16$ & 0.47 & 0.56 & 0.04 & 0.42 & 0.00 & 0.52 \\
\hline$\Delta$ Power Mass ${ }^{-1} / \mathrm{W} \mathrm{kg}^{-1}$ & $2.77 \pm 0.13$ & $2.64 \pm 0.16$ & 0.52 & 0.43 & 0.03 & 0.05 & 0.98 & 0.03 \\
\hline Power BSA ${ }^{-1} / \mathrm{W}\left(\mathrm{m}^{2}\right)^{-1}$ & $146.45 \pm 11.08$ & $132.01 \pm 13.39$ & 0.07 & 3.79 & 0.24 & & & \\
\hline MET $_{\text {start }}$ & $3.13 \pm 0.17$ & $3.00 \pm 0.21$ & 0.63 & 0.2491 & 0.02 & 7.14 & 356.19 & 7.12 \\
\hline $\mathrm{MET}_{\text {end }}$ & $14.74 \pm 0.69$ & $11.73 \pm 0.85$ & 0.02 & 7.5455 & 0.37 & 0.02 & 0.00 & 0.02 \\
\hline$\Delta \mathrm{MET}$ & $11.61 \pm 0.68$ & $8.73 \pm 0.83$ & 0.02 & 7.1269 & 0.35 & 0.35 & 0.96 & 0.35 \\
\hline $\mathrm{EE}_{\text {start }} / \mathrm{kcal}^{-\mathrm{d}^{-1}}$ & $75.11 \pm 4.38$ & $73.33 \pm 5.36$ & 0.80 & 0.0660 & 0.00 & 7.00 & 381.40 & 7.54 \\
\hline $\mathrm{EE}_{\text {end }} / \mathrm{kcal} \mathrm{d}^{-1}$ & $365.55 \pm 16.68$ & $292.17 \pm 20.43$ & 0.02 & 7.7431 & 0.37 & 0.02 & 0.00 & 0.016 \\
\hline$\Delta \mathrm{EE} / \mathrm{kcal} \mathrm{d}^{-1}$ & $290.44 \pm 18.24$ & $231.50 \pm 22.34$ & 0.06 & 4.1754 & 0.24 & 0.35 & 0.97 & 0.38 \\
\hline
\end{tabular}

$V O_{2 \text { start }}$ oxygen uptake at beginning of exercise, $V O_{2 \text { end }}$ oxygen uptake at the end of exercise, $H R$ start heart rate at beginning of exercise, $H R$ end heart rate at the end of exercise, $M E T_{\text {start }}$ metabolic energy equivalent at beginning of exercise, $M E T_{\text {end }}$ metabolic energy equivalent at the end of exercise, $E E_{\text {start }}$ energy expenditure at beginning of exercise, $E E_{\text {end }}$ energy expenditure at the end of exercise, $B S A$ body surface area

Besides, gender differences may be associated with higher $\mathrm{VO}_{2}$ max in the male cross-country skiers similar to other endurance athletes, which was partly explained by higher hemoglobin levels and lower body fat in men [25, 26]. However Jay et al. [27] indicated that large differences in $\mathrm{VO}_{2}$ peak between individuals do not influence changes in core temperature or sweating during exercise in a neutral climates, regardless of metabolic heat production, body mass, and BSA.

The thermographic records show the complex physiological response to exercise that involves the skeletal muscle (metabolism), the cardiovascular system (blood flow), the nervous system (central and peripheral) and the adrenergic system [15]. One of the main factors affecting the resting skin surface temperature under conditions of thermal comfort is vascular control.

Among the analyzed infrared thermography (IRT) parameters by us, $T_{1}$ showed the strongest significant differences due to gender. Before exercise women were characterized by lower skin temperature than men what is in agreement which literature, e.g., Davies, Chudecka, Lubkowska [28, 29]. The lowest mean temperatures in obese women were observed in the areas of the abdomen and thighs, corresponding to the areas with the greatest accumulation of body fat, and therefore suggesting that its insulating function hindered heat conduction at rest [5].

The lower skin temperature in female than in male was reported in trained athletes in morning and during the day, while at evening this differences disappeared [30]. In untrained individuals this relation was presumed to be related with body fat, BMI and gender [29, 31]. Another study confirmed this in children [32] and showed the distribution of body surface temperature was differed in boys and girls. However, in our study, the temperature in the lower limb muscles of the athletes increased after exercise, in contrast to the results presented by Dęmbiec-Bak et al. [32] where the temperature in all parts of the children's bodies decreased. This may suggest a different response to exercise in children compared to trained adults. Our results of skin temperature for the lower extremities are consistent with those obtained by Chudecka et al. for men and women [9].

Dynamic exercise results increase metabolic heat production that in turn requires thermoregulatory skin blood flow to increase in order to limit the elevation in core temperature. 
Kenny et al. [33] demonstrated that women show significantly greater and more prolonged elevations in post-exercise body temperatures and deep-to-superficial active and inactive muscle temperatures relative to men. According to Notley et al. [10], typical females displaying greater forearm blood flow and vascular conductance at rest and during work. On the other hand, adaptation of body to specified exercise may cause some changes in thermal mapping what was suggested earlier by, Tanda [34], Merla et al. [17] and Ludwig et al. [35].

In our work, we showed that exercise induces changes in skin temperature in all participants. Changes of skin temperature in response to exercise in the same muscle zones were depended on the gender of participants. A greater increase in skin temperature was obtained in women compared to men.

It follows from literature that the temperature changes during exercise depend on the type of muscle involved in the sport. Merla et al. [17] obtained that peripheral region (arms) were cooled faster than trunk and Duygu [36] showed differences in temperature response of quadriceps and hamstring in sailors after aerobic and anaerobic test. Drzazga et al. [11] reported that changes of skin temperature after exercise were different for swimmers and cross-country skiers for different muscle zones. Comparison of effect of exercise on skin temperature in trained and untrained female was presented by Formenti [37]. Tanda [34] pointed out a decrease of skin temperature in professional runners due to exercise suggesting that it was connected with vasoconstriction while rise temperature after training with vasodilation. Sex-related differences in end-exercise mean blood flow of the inactive triceps brachii were not observed in Kenny, and Jay [33].The authors suggested a greater convective heat transfer from deeper tissues to the periphery in males leading to smaller elevations in inactive muscle temperature. Even though elevations in active muscle temperature tended to be greater in females at the end of exercise, no significant differences were found between the sexes, possibly suggesting a less prominent sex difference in active mean blood flow.

During the post-exercise recovery period, temperature returned quickly to bias in men unlike women. Marins et al. [13] observed a slower thermal progression in men compared to women. Such phenomena could be related with different distribution and activity of sweat glands in the both studied groups and differences in vasomotor response following the cessation of exercise. Differences in sweat glands capacity were described by Gagnon and Kenny, whose showed that males produces more sweat than females and also capacity of sweat glands is greater in men group than women [9]. Kuwahara et al. [8] also confirmed a greater increase in sweating rate in males than in females and suggested that the degree of training does not affect the difference in sweating between the genders. The increase in skin temperature in women observed in our experiment immediately after exercise may be due to greater heat storage and slower heat exchange in women than in men, which is due to the greater latency time of sweating and the lower sensitivity of this thermoregulatory response to increases in body temperature as suggested by Bittel and Hennen $[4,38]$ well as Pokora and Grucza [4].

An another way to understand differences in skin temperature response to exercise in men and women is through differences in the regulation of cutaneous blood flow. A greater rise of temperature prolonged in time after exercise in women was reported earlier be Kenny and Jay [33] who connected this result with post-exercise reduction in vascular resistance corresponding to vasodilation. A similar effect was obtained by Tanda [39] however only in preliminary studies. Physical exercise caused an increase in blood nitric oxide (NO), which plays an important role in the vasodilation of cutaneous arterioles. Given the need for local metabolic heat loss, NO could promote vasodilation in areas subjected to exercise through a mechanism called prolonged plateau NO-dependent vasodilation [40], allowing increased blood flow and causing an increase in local temperature, which was recorded by thermal imagers.

Therefore, differences in body morphology are of primary importance to understanding inter-individual variations in both passively and autonomically driven heat exchange in physically diverse, mixed-sex populations [1]. In addition, the significant gender differences in sweating dynamics and the ability to dissipate heat by sweat evaporation in men and women appear to be related to the fact that women utilize skin cutaneous vasodilation to a greater extent than men to dissipate heat [9].

\section{Conclusions}

Thermal mapping showed that skin temperature of the lower limbs in female cross-country skiers was lower than in male, especially before exercise. Changes in skin temperature in response to exercise were significantly greater in women than in men, and higher skin temperature persisted in women during the recovery period. This may indicate that skin temperature regulation in response to exercise with similar external workload was modified by gender in high-trained cross-country skiers. The gender differences obtained in our study appear to be related to the different sweating dynamics and the ability to dissipate heat by sweat evaporation in men and women, as well as to differences in the contribution of skin vasodilation to the removal of excess heat generated by active muscles during exercise. In addition, gender of the respondents statistically significantly differentiated oxygen uptake $\left(\mathrm{VO}_{2}\right)$, metabolic energy equivalent (MET) and amount of energy expended (EE) in contrast to HR and power mass ${ }^{-1}$ index during the exercise test. 


\section{Practical suggestions for coaches}

Our study showed that thermography can be useful to plan specified training to individual persistence of athletes taking into account gender. Results suggested that female and male sportsmen may need a little different training plans, what is in line with results obtained in individuals performing other sports. This individual approach to training plans based on thermographic imaging is being implemented gradually at the Jerzy Kukuczka Academy of Physical Education in Katowice.

\section{Limitations}

Our study has some limitations. We did not take into consideration the menstrual cycle of the female subjects when analyzing the data in the present study. Moreover, our research groups were relatively small, especially woman group.

One limitation of this study was the lack of quantification of fat tissue thickness in the studied muscles. This information would have facilitated our understanding of certain thermal skin responses on the lower limb areas.

\section{Declarations}

Conflict of interest The authors declare no conflicts of interest.

Open Access This article is licensed under a Creative Commons Attribution 4.0 International License, which permits use, sharing, adaptation, distribution and reproduction in any medium or format, as long as you give appropriate credit to the original author(s) and the source, provide a link to the Creative Commons licence, and indicate if changes were made. The images or other third party material in this article are included in the article's Creative Commons licence, unless indicated otherwise in a credit line to the material. If material is not included in the article's Creative Commons licence and your intended use is not permitted by statutory regulation or exceeds the permitted use, you will need to obtain permission directly from the copyright holder. To view a copy of this licence, visit http://creativecommons.org/licenses/by/4.0/.

\section{References}

1. Taylor NAS, Notley SR. Morphological and physiological considerations for the modelling of human heat loss. Theory Appl Heat Transf Humans. 2018. https://doi.org/10.1002/9781119127420. ch22.

2. Kaciuba-Uscilko H, Grucza R. Gender differences in thermoregulation. Curr Opin Clin Nutr Metab Care. 2001. https://doi.org/10. 1097/00075197-200111000-00012.

3. Pokora I, Grucza R. Effects of low-carbohydrate diet on thermoregulatory responses to graded exercise in men. Biol Sport. 2000; $17: 275-88$.
4. Pokora I, Grucza R Influence of a low-carbohydrate diet on thermoregulatory responses to exercise in women during follicular and luteal phase of the menstrual cycle. Biol Sport 200; 17(1): $13-24$.

5. Chudecka M, Lubkowska A, Kempińska-Podohordecka A. Body surface temperature distribution in relation to body composition in obese women. J Therm Biol. 2014;43:1-6.

6. Shapiro Y, Pandolf KB, Avellini BA, Pimental NA, Goldman RF. Physiological responses of men and women to humid and dry heat. J Appl Physiol. 1980;49:1-8.

7. Inoue Y, Tanaka Y, Omori K, Kuwahara T, Ogura Y, Ueda H. Sex- and menstrual cycle-related differences in sweating and cutaneous blood flow in response to passive heat exposure. Eur J Appl Physiol. 2005;94:323-32.

8. Ichinose-Kuwahara T, Inoue Y, Iseki Y, Hara S, Ogura Y, Kondo N. Sex differences in the effects of physical training on sweat gland responses during a graded exercise. Exp Physiol. 2010. https://doi.org/10.1113/expphysiol.2010.053710.

9. Gagnon D, Kenny GP. Does sex have an independent effect on thermoeffector responses during exercise in the heat? J Physiol. 2012;590(23):5963-73. https://doi.org/10.1113/jphysiol.2012. 240739.

10. Notley SR, Park J, Tagami K, Ohnishi N, Taylor NAS. Variations in body morphology explain sex differences in thermoeffector function during compensable heat stress. Exp Physiol. 2017;102:545-62. https://doi.org/10.1113/EP086112.

11. Drzazga Z, Binek M, Pokora I, et al. A preliminary study on infrared thermal imaging of cross-country skiers and swimmers subjected to endurance exercise. J Therm Anal Calorim. 2018;134:701-10. https://doi.org/10.1007/s10973-018-7311-y.

12. Drzazga Z, Cholewka A, Ciszek W, Czuba MC, Poprzecki S. Body temperature depression to training exercise in normobaric hypoxia_primary studies. In: IFMBE proceedings; 2015; 45: pp. 232-235.

13. Marins JCB, Fernandez-Cuevas I, Arnaiz-Lastras J, Fernandes AA, Sillero-Quintana M. Applications of infrared thermography in sports. a review. Revista Internacional de Medicina y Ciencias de la Actividad F1'sica y el Deporte. 2015;15(60):805-24.

14. Hreljac A. Etiology, prevention, and early intervention of overuse injuries in runners: a biomechanical perspective. Phys Med Rehabil Clin N Am. 2005;16:651-67. https://doi.org/10.1016/j. pmr.2005.02.002.

15. Fröhlich M, Ludwig O, Kraus S, Felder H. Changes in skin surface temperature during muscular endurance indicated strain-an explorative study. Int J Kinesiol Sports Sci. 2014;2(3):23-7.

16. Moreira DG, Costello JT, Brito CJ, et al. Thermographic imaging in sports and exercise medicine: a Delphi study and consensus statement on the measurement of human skin temperature. J Therm Biol. 2017;69:155-62. https://doi.org/10.1016/j.jther bio.2017.07.006.

17. Merla A, Mattei PA, Di Donato L, Romani GL. Thermal imaging of cutaneous temperature modifications in runners during graded exercise. Ann Biomed Eng. 2010;38:158-63. https://doi. org/10.1007/s10439-009-9809-8.

18. Ammer K. The Glamorgan Protocol for recording and evaluation of thermal images of the human body. Thermol Int. 2008;18(4):125-44.

19. Fernandez-Cuevas I, Sillero-Quintana M, Garcia-Conception MA, Ribot-Serrano J, Gomez-Carmona P. Monitoring skin thermal response to training with infrared thermography. New Stud Athl. 2014;29(1):57-71.

20. Austin DM, Lansing MW. Body size and heat tolerance: a computer simulation. Hum Biol. 1986;58:153-69.

21. Gagnon D, Jay O, Lemire B, Kenny GP. Sex-related differences in evaporative heat loss: the importance of metabolic heat production. Eur JAppl Physiol. 2008;104:821-9. 
22. Gagnon D, Dorman LE, Jay O, Hardcastle S, Kenny GP. Core temperature differences between males and females during intermittent exercise: physical considerations. Eur JAppl Physiol. 2009;105:453-61.

23. Schwiening CJ, Mason MJ, Thompson M. Absolute power, not sex, promotes perspiration. Exp Physiol. 2011;96:556-8.

24. Jay O. Unravelling the true influences of fitness and sex on sweating during exercise. Exp Physiol. 2014;99:1265-6.

25. Sandbakk $\varnothing$, Ettema G, Leirdal S, Holmberg H-C. Gender differences in the physiological responses and kinematic behaviour of elite sprint cross country skiers. Eur J Appl Physiol. 2012;112:1087-94. https://doi.org/10.1007/s00421-011-2063-4.

26. Calbet JA, Joyner MJ. Disparity in regional and systemic circulatory capacities: do they affect the regulation of the circulation? Acta Physiol. 2010;199(4):393-406.

27. Jay O, Bain AR, Deren TM, Sacheli M, Cramer MN. Large differences in peak oxygen uptake do not independently alter changes in core temperature and sweating during exercise. Am J Physiol Regul Integr Comp Physiol. 2011. https://doi.org/10.1152/ajpre gu.00257.2011.

28. Davies CTM. Thermoregulation during exercise in relation to sex and age. Europ J Appl Physiol. 1979;42:71-9. https://doi.org/10. 1007/BF00421907.

29. Chudecka M, Lubkowska A. Thermal maps of young women and men. Infrared Phys Technol. 2015;69:81-7.

30. Bouzas Marins JC, Formenti D, Magno A, Costa C, de Andrade FA, Sillero-Quintana M. Circadian and gender differences in skin temperature in militaries by thermography. Infrared Phys Technol. 2015;71:322-8.

31. Neves EB, Salamunes ACC, de Oliveira RM, Stadnik AMW. Effect of body fat and gender on body temperature distribution. $\mathrm{J}$ Therm Biol. 2017;70:1-8.

32. Dębiec-Bąk A, Kuligowski T, Skrzek A. Analyzing thermoregulation processes in early school-age girls and boys through thermography. J Therm Anal Calorim. 2020;140:243-51. https://doi.org/ 10.1007/s10973-019-08843-z.
33. Kenny GP, Jay O. Sex differences in postexercise esophageal and muscle tissue temperature response. Am J Physiol Regul Integr Comp Physiol. 2007. https://doi.org/10.1152/ajpregu.00638.2006.

34. Tanda G. Skin temperature measurements by infrared thermography during running exercise. Exp Therm Fluid Sci. 2016;71:103-13.

35. Ludwig N, Trecroci A, Gargano M, Formenti D, Bosio A, Rampinini E, Alberti G. Thermography for skin temperature evaluation during dynamic exercise, a case study on an incremental maximal test in elite male cyclist. Appl Opt. 2016;55(34):1-5. https://doi.org/10.1364/AO.99.099999.

36. Cerezci Duygu S, Ozunlu Pekyavas N, Uzun A, et al. Muscle skin temperature responses for hamstring and quadriceps to aerobic and anaerobic test conditions in Turkish olympic sailing athletes. $\mathrm{J}$ Therm Anal Calorim. 2019;136:2125-30. https://doi.org/10.1007/ s10973-018-7865-816.

37. Formenti D, Ludwig N, Gargano M, Gondola M, Dellerma N, Caumo A, Alberti G. Thermal Imaging of exercise-associated skin temperature changes in trained and untrained female subjects. Ann Biomed Eng. 2013. https://doi.org/10.1007/s10439-012-0718-x.

38. Bittel J, Henane R. Comparison of thermal exchanges in men and women under neutral and hot conditions. J Physiol. 1975;250:475-89.

39. Tanda G. The use of infrared thermography to detect the skin temperature response to physical activity. J Phys: Conf Ser. 2015. https://doi.org/10.1088/1742-6596/655/1/012062.

40. Johnson JM, Kellogg DL Jr. Local thermal control of the cutaneous circulation. J Appl Physiol. 2010;109:1229-38.

Publisher's Note Springer Nature remains neutral with regard to jurisdictional claims in published maps and institutional affiliations. 